\title{
Performance of Equipment Productivity for Highway Projects - A Review
}

\author{
Mr. Ghanasham C. Sarode, Dr. D. Y. Patil Institute of Technology, Pimpri, Pune India, \\ ghanasham_sarode01@ rediffmail.com \\ Dr. Pankaj P. Bhangale, Shri Sant Gadge Baba College of Engineering and Technology, Bhusawal, \\ India.pankajpbhangale@gmail.com
}

\begin{abstract}
The largest share of investment capital in all developing countries finds its way in to construction. In our India construction industry are growing rapidly. The development of construction industry is the bare for all industrial activities in any developing country, since the economic progress depends on the investment of the capital for future production; the rate of construction activity has a significant effect upon the economic health of the nation and its future growth. Construction equipment plays a significant role in the execution of modern high-cost time-bound construction projects. Equipment is an economic investment and the contractors must apply time value analytical formula to the process of machine utilization. The most important aspect of estimating and building a construction project is determining production and cost and controlling both during the progress of work. The planning $\&$ selection of equipment is depends upon construction structure, location, and various construction methods. Also that depends on various construction operations. This study emphasizes the vital role of construction equipment in construction industries to optimize the profit by reducing the labour hours and also aimed to identifying the best practices of improving the productivity of construction for the Indian scenario. With this aid planning would be more systematic, logical and efficient as resource allocators and managers would be aware of output for particular equipment.
\end{abstract}

Keywords - Equipment planning, selection and management, Equipment productivity, Equipment Maintenance, Safety Measures, Road Construction, Optimization

\section{INTRODUCTION}

The construction project is best described as an amalgam of wide varieties of economic activities ranging from house building and repair to major engineering works. Drawing the boundaries of construction industry is an arduous task but an operational definition which recognizes the construction industry to include firms and individuals involved in planning, design, the supply of building materials, plant, equipment, transport and other services relating to the procurement of physical infrastructure and services.

The infrastructure development is an important aspect for the overall development of country. India is considered as the hub for service industry for which the infrastructure development plays an important role. Highway construction projects are the benchmark to measure the development of country. Now the highway construction projects are changing their face. Due to "Public Private Participation" in highway projects, it has become a challenging job to complete the project in stipulated time. BOT type of contract of highway construction projects enforces the contractors to complete the project as early as possible to start the regaining the investments through the toll. The cost of equipment in a project varies from $10-30 \%$ of the total cost of project, depending upon the extent of mechanisation. Proper planning, selection, procurement, installation, operation, maintenance, safety and equipment replacement policy plays an important role in equipment management for successful completion of project. With the growing use of machinery it has become necessary for construction engineers to be thoroughly familiar with the construction application and upkeep of the wide range of modern equipment. Construction of any project is a business region that trusts primarily on high utilization of construction equipment. Currently in Jalgaon \& Bhusawal city, the Road construction sector plays an important role in short term tendencies, with more development, not only for the region itself but also for other economic activities as well. As a output, it is definitely supposed to do that the road construction industry needs an effective resource organization practice to retain profitability and continue its actively contribution to the growth of the country. Large scale construction activities like road-making, construction 
of rail-roads, canals, irrigation and power dams, development of building sites, airports and harbors are clear indicators of growth of a developing country. The activities of a construction projects have been growing very steadily commensurate with the requirement of power, communication, transportation and agricultural output of a developing nation like India.

\section{A. A. Need of Study:}

Archimedes said, "Give me a lever and point to support it, I will move the earth". Engineers always aim to use mechanical advantage and velocity ratio to get maximum output with available input. The same principles are used in construction equipment in a sophisticated way. We use prime mover and power instead of manual labour. In short, construction equipment's can be defined as machines to give desired/designed output with available input, using simple devices as pulley, lever wheel and the axle in one way or other. The performance of an equipment / plant is affected by local conditions which will vary at different sites. Even where detailed reconnaissance has been possible and reasonable sound knowledge of these conditions has been obtained, accurate estimation of performance and hence of output of different machines and teams of machines requires considerable knowledge and experience. Guesstimating needs to be avoided whenever possible. Where lack of time necessitates a guesstimate, the fact that it is guessing must be made clear and stressed. Viewing these factors it becomes essential for contractors to optimize resources through effective planning of equipment's. The performance of construction equipment in terms of production rate is required to be assessed in order to calculate the number and size of equipment and to decide on the matching size of other equipment. The production rate is also used in calculating cost of machine work for preparing cost estimates and for cost control.

Highway construction involves a combination of dedicated administrations, engineering knowledge, studied presumptions, and calculated threats. Since operations must be performed at the site of the project, often affected by planning and management difficulties, every project is unique. The aim of this study is therefore, to study the difficulties and the way in which construction equipment planning, selection and management is used in highway construction projects, improving the productivity of equipment, evaluate the suitability, to understand some construction equipment planning, management and utilization of construction equipment practices used for construction of highway project.

\section{LITERATURE REVIEW}

Today, India is the second fastest growing economy in the world. The Indian construction industry is an integral part of the economy and a conduit for a substantial part of its development investment, is poised for growth on account of industrialization, urbanization, economic development and people's rising expectations for improved quality of living. In India, construction is the second largest economic activity after agriculture. Construction accounts for nearly 65 per cent of the total investment in infrastructure and is expected to be the biggest beneficiary of the surge in infrastructure investment over the next five years. Investment in construction accounts for nearly 11 per cent of India's Gross Domestic Product (GDP). € 239.68 billion is likely to be invested in the infrastructure sector over the next five to 10 years - in power, roads, bridges, city infrastructure, ports, airports, telecommunications, which would provide a huge boost to the construction industry as a whole. The 10th five year plan brought by Planning commission, Government of India, which is a policy paper for the economy for period 2002-2007 had for first time incorporated a chapter on Construction. This shows the importance given by the Government of India to the Construction Industry. The plan encourages $8 \%$ growth in GDP for which total development outlay, 639 crore allocated for the 2002-07 period. The investment in construction is about $40 \%$ to $50 \%$ of the same which is Rs. $1,22,051$ crore annual additional (For new development) investment in construction. For the $11^{\text {th }}$ Five year plan (for the period 2007-2012) it is proposed to enhance the investment in infrastructure two folds.

There are inadequate researches already conducted on analysis of construction equipment planning, selection and management complications in highway construction project. Thus, this studies are concentrated on improving productivity of construction equipment on highway project; therefore it is better to conduct detail study on equipment planning, selection \& management complications to moderate the causes and effects of problems on safety \& maintenance of equipment. Such research work done in various countries in the following way;

Aakash P. Mohane, Harshita P. Ambre (2019), evaluate \& studied equipment management tools is mostly required in planning and controlling the quality and quantity of the equipment, punctual equipment placement, good price and the right quantity as required. This study presents the identification of problems of construction equipment planning and management for road projects. For achieving the objectives of project work they were conducted data through various questionnaire, interview and case studies; Interpretations and discussions were made on the basis of the results from the analysis of past research work and questionnaire survey. They found that most companies have no documented construction equipment planning and management policy; also the result indicated that idle time, down time, poor equipment maintenance practices are some of major problems that affect construction equipment planning and management. 1 
Y.R.Anbhule and Prof. M.B.Kumthekar (2019) studied effective management of equipment is crucial for the success of construction firms. Inadequate manual processes of equipment management and the subjective decisions of equipment managers usually result in major losses in construction firms, hence, the economy. Highway construction projects are the yardstick to measure the development of country. Now the highway construction projects are changing their face. Due to "Public Private Participation" in highway projects, it has become a challenging job to complete the project in stipulated time.3D equipment management system deals with Proper planning, selection and optimum utilisation of construction equipment for highway construction project. ${ }^{2}$

M. Manikandan, et al., (2018) analysed and studied construction equipment management with respect to improve productivity He suggested improving productivity it is essential to improve the performance of construction systems, productivity will be achieved through high equipment availability which is influenced by equipment reliability and maintainability. ${ }^{3}$

According to N. Shyamananda Singh (2018), Highway construction projects uses huge amount of resources on and off the field in the form of plants and equipments due to time and quality constraints. The present study is mainly concentrated on equipment productivity along with different performance measurement. Case study was carried out at selected highway projects sites and presents in two parts. Part I of the study highlight the site specific performance and cost economics of equipments. The data were analyzed on the basis of their availability, utility, performance, production rate and cost components. . The availability of the equipments show a very high percentage (90-98) \% indicating that the equipments are well organized, properly maintained and within the site. The total cost of the equipments is mostly proportional to the energy cost with $(60-70) \%$ of the total expenditure. ${ }^{4}$

Mekdim Mathewos (2017), studied the construction equipment planning and management problems in road construction projects. He carried out survey where most of the respondents agreed that maintenance is very important part of equipment management which directly affects the cost of operation of any equipment. ${ }^{5}$

Shinde V. J., Hedaoo M. N. (2017), studied the productivity level of construction industry is mostly depending upon three factors they are labour characteristics, management systems and external issues. Different researchers have determined different factors that influence construction productivity. Understanding the level of productivity, it is important to develop innovative practices to improve construction productivity ${ }^{6}$

A. Salem, A. Salah, M. Ibrahim, and O. Moselhi (2017) analysed that, earthmoving operations and highway construction commonly entails extensive utilization of heavy construction equipment. Various factors affect directly and indirectly the efficient utilization of equipment and subsequently can lead to productivity decline in earthmoving operations. Efficient utilization of equipment is considered a crucial element towards the success of earthmoving project. $^{7}$

According to Sachin Pindoria, Dr. Jayeshkumar Pitroda, Dr. H.V. Patel (2017), Output of the any equipment per minute, hour or day is called the productivity of the equipment. Study the Productivity relating to the construction equipment is very useful to decide the fair or rent of the equipment. ${ }^{8}$

Samson Mekbib Atnaw, et al., (2016) studied a case study on road construction equipment management in Malaysia in which they they concluded use of solutions methods based on minimization of cost and maximization of profit modules implementations will help in optimum decision making. ${ }^{9}$

Murodif atfal et al (2016) research objective was to analyze the productivity with the help of work sampling method. Their data sampling method was;

1) To classify workers activities in three groups (effective work, essential contributory work, and inefficient work)

2) Collection of data from field observation results in particular order.

3) Taking randomized observational result data.

4) Then checklist is created for the workers activity.

5) Add all checked workers activities and then percentages calculation.

Then after labour utilization rate (LUR) is calculated in percentage. The results of LUR analysis where obtained was for formwork it was $47.32 \%$, for reinforcement it was $43.17 \%$ and for concreting it was $49.76 \%$. The total value of LUR of all three works was $45.60 \%$. ${ }^{10}$

Kartik Shard Thete and Dhiraj Rajendra Baviskar (2016) studied the Construction Equipment management in which they gave more importance to selection of equipment and discussed selection of equipment depends upon site conditions, duration of work and its overall cost of operation. It is an engineer's responsibility to assign a particular equipment to complete a task as per site conditions. As there are large number of equipments available in the market it becomes a difficult task to select the equipment depending upon its productivity \& other responsible factors. ${ }^{11}$

Prajeesh. V. P. \& Mr. N. Sakthivel (2016), In this study Construction equipment is a major resource in the building process for a construction project. When equipment is owned by a contractor, it forms a sizable portion of his assets requiring proper management practices. Good project management in construction must vigorously 
pursue the efficient utilization of labor, material and equipment. The use of new equipment and innovative methods has made possible wholesale changes in construction technologies in recent decades. The selection of the appropriate type and size of construction equipment often affects the required amount of time and effort and thus the job-site productivity of a project. It is therefore important for site managers and construction planners to be familiar with the characteristics of the major types of equipment most commonly used in construction. ${ }^{12}$

David Ngwoke Mbazor and Sunday Okuoma Okoh (2015) have Productivity Improvement in Construction Project Delivery. Productivity is a complex phenomenon at all levels be it individual, organised private sector or government the world over and in all spheres of human endeavour particularly in construction project delivery. Low productivity in the construction industry is as a result of diverse identifiable reasons such as; high reduction in skill level of construction workers, shift work, shortages of materials and equipment, change orders, labour shortages, weathers, low level of monitoring and control of projects etc. key factors that leads to productivity improvement in construction project delivery were analysed. These comprise of project planning, productivity measurement, avoidance of construction site congestion, motivation of workforce and good communication among others. It was therefore recommended that time management, application of project management tools like pert master, precedence diagram, research and development, provision of new equipment, plant and machinery to replace the old ones, simplifying the product variety, increasing the overall effectiveness of the workforce through motivation and paying attention to details of the current best practices in the industry will no doubt lead to productivity improvement in construction project delivery. ${ }^{13}$

Prasannasangeetha.A, Alan. (2015), said that, Construction equipment plays great significant role in construction industry, costs as high as $36 \%$ of the total construction project expense, however, the equipment maintenance has not been given appropriate attention and this contribute to about $40 \%$ of total construction project cost overrun. $^{14}$

Saurabh Rajendra Kadam, Prof. Dhananjay S Patil (2015), studied large numbers of construction equipment are required on construction site. The efforts of contractors are to constantly push machine capabilities forward. As the array of useful equipment expand, the importance of careful planning and execution of construction equipment's increases. ${ }^{15 .}$

Shashank K .et al (2014) they put a theoretical model for productivity improvement as reliability analysis, factor analysis, and multiple linear regression analysis. They conducted a questionnaire survey in which they got 53 responses out of 60 questioners after that reliability analysis was conducted to find out average correlation between data the method used for that is split-half method. Then factor analysis that is statically technique which identifies the common component then followed by multiple regressions $\&$ hypothesis testing. ${ }^{16}$

Abebaw Worku Dagne (2014), in this study Equipment may range from simple hand tools or apparatus to heavyduty construction equipment. As a high level of productivity is important to any company's success and survival, this paper help to fill the gap created by the absence of proper equipment management on the construction sites and helps to examine the overall performance of heavy-duty construction equipment. The OEE index show low percentage of productivity in between $55 \%$ to $68 \%$. Out of the three primary component rates of OEE index only quality rate have a higher performance, which is about $90 \%$ and above. However, the performance rate in the entire study site shows lower performance(less than $76 \%$ ). Out of the four main contributing factors for equipment productivity loss (machine factor, human factor, management factor and work factor) the management problem ranked first. ${ }^{17}$

Dolage \& chan (2013) Main objective was to measurement of productivity \& finding the casual relationships with productivity they studied old articles \& they found that

1) What type of productivity is being examined?

2) At what level productivity is examined.

3) Data collection method approach.

4) Main objectives of investigation.

They found that research objectives are of six different groups as measurement, assessment of improvement, identification \& ranking of factors, influence \& relationship. They concluded that there is a lack of positive approach in the earlier research \& the methodologies that are used are not up to date for exact findings. ${ }^{18}$

Sri. Nuwan Randunupura and Chandanie Hadiwattege (2013) studied plant and equipment management to minimize delays in road construction in which they have reviewed plant and equipment selection practices. $^{19}$

Mohammed Faiz (2013) in this study, the author studied operation of the hydraulic excavator from the data obtained by monitoring the machine during regular operation period. The objective of the work is to build an understanding of how machine usage affects performance, extending across productivity and to provide an analytical approach for identifying causes of productivity loss, evaluating their performance and to understand how the machine is used and how different method of use relates to its productivity and reliability. The actual job operating condition which might 
affect productivity were identified and recorded which includes causes of material, operator's skill, condition of hoe, haul unit exchange, site of hauling unit, height of cut etc. The time-motion study was conducted and productivity, total cycle time and cycle time of element were estimated for each equipment with respect to bucket size. The estimations were made following the guidelines given in the manufacturer's performance handbook. The actual productivity was then calculated based on the data obtained from site. The term Production Performance Ratio (PPR) was used to compare the actual productivity against estimated productivity to demonstrate the amount of loss of productivity. This Production Performance Ratio was found to be less than 1 which indicated that, the equipment failed to perform as per it was expected to be. It is cleared by the author that, all seconds saved per cycle meant nothing if the hydraulic excavator did not have trained operator. ${ }^{20}$

Parviz Ghoddousi and Mohammad Reza Hosseini (2012) analysed a survey of the factors affecting the productivity of construction projects in Iran. The intense competition between the Iranian construction companies has led them to take all appropriate measures to decrease the costs as much as possible. ${ }^{21}$

Kyong Ju Kim K. and Kyoungmin Kim (2010), the purpose of this study is to evaluate the effects of traffic flow of construction equipment. A large construction project requires large quantities of construction equipment. This volume can result in traffic congestion in the flow of construction equipment, which also lowers the overall efficiency of construction operations. In particular, this effect can be serious in the area where traffic bottlenecks are most likely. ${ }^{22}$

According to Osama Moselhi, F.ASCE; and Adel Alshibani (2009), large scale earthmoving operations require the use of heavy and costly construction equipment. Optimum utilization of equipment is a crucial task for the project management team. It can result in substantial savings in both time and cost of earthmoving operations. This paper presents optimization model for earthmoving operations in heavy civil engineering projects. The developed model is designed to assist general contractor in optimizing planning of earthmoving operations. The model utilizes genetic algorithm, linear programming, and geographic information systems to support its management functions. The model assists in planning earthmoving operations; taking into consideration: (1) availability of resources to contractors; (2) project budget and/or time constraints, if any; (3) scope of work; (4) construction site conditions; (5) soil type; (6) project indirect cost; and (7) equipment characteristics. The model also determines the quantities of earth to be moved from different borrow pits and those to be placed at different landfill sites to meet optimization objective set by the user and to meet project constraints. The model has been implemented in prototype software, using object-oriented programming. ${ }^{23}$

According to Seung C. ok \& Sunil K.Sinha (2006), estimating equipment production rates is both an art and a science. An accurate prediction of the productivity of earthmoving equipment is critical for accurate construction planning and project control. Owing to the unique work requirements and changeable environment of each construction project, the influences of job and management factors on operation productivity are often very complex. Hence, construction productivity estimation, even for an operation with well known equipment and work methods, can be challenging. 24

Aviad Shapira and Marat Goldenberg (2005), studied \& analysed Selection of equipment for construction projects, a key factor in the success of the project, is a complex process. Current models offered by the literature fail to provide adequate solutions for two major issues: the systematic evaluation of soft factors, and the weighting of soft benefits in comparison with costs. ${ }^{25}$

By Chiara F. Ferraris (2001), As for all materials, the performance of concrete is determined by its microstructure. Its microstructure is determined by its composition, its curing conditions, and also by the mixing method and mixer conditions used to process the concrete. The paper gives an overview of the various types of mixing methods and concrete mixers commercially available used by the concrete industry. There are two main types of mixers used: batch mixers and continuous mixers. Batch mixers are the most common. To determine the mixing method best suited for a specific application, factors to be considered include: location of the construction site (distance from the batching plant), the amount of concrete needed, the construction schedule (volume of concrete needed per hour), and the cost. Ultimately, the quality of the concrete produced determines its performance after placement. An important measure of the quality is the homogeneity of the material after mixing. The paper will review mixing methods in regards to the quality of the concrete produced. Some procedures used to determine the effectiveness of the mixing will be examined. ${ }^{26}$

Mitchell W. Zane (1998) studied \& analyzed that, the management of heavy construction equipment is a difficult task. Equipment managers are often called upon to make complex economic decisions involving the machines in their responsibility. These decisions include those concerning purchase, maintenance, repairs, reconstructs, replacements, and retirements. Repair and maintenance expenditures can have significant impacts on these economic decisions and forecasts. The purpose of this research was to identify a regression model that can adequately represent repair costs in terms of machine age in cumulative hours of use. The study was conducted using field data on 270 heavy 
construction machines from four different companies. Nineteen different linear and transformed non-linear models were evaluated. $^{27}$

According to Jones, R. P., selection of the proper equipment to suit the job conditions is the contractor's responsibility. Extensive studies in handling various types of materials with various types and sizes of equipment will aid the contractor to select the proper equipment to perform the work in the most economical manner. More detailed investigation of the excavation to be encountered will also aid the bidder to determine the most suitable equipment to handle the material. This will avoid costly changes in equipment and unnecessary delays during the progress of the work. Power shovels and draglines are necessary to excavate certain materials. It is desirable for the contractor to select a machine as large as can be justified, dependent upon the size of the project and the nature of the material to be handled, in order to obtain the lowest handling cost. Some of these are classed as management factors and require careful study to operate efficiently. Studies have been made which point out considerable lost time due to these factors. Further studies of this nature will be beneficial to contractors and manufacturers. ${ }^{28}$

\section{SUMMARY OF OBSERVATIONS}

As per the data analyze \& studied by authors in the various papers, performance of equipment productivity in construction industry is depends on various factors affecting on planning, selection \& management of equipment \& manpower as per their position of work in a highway projects. Construction equipment is one of the main contributions of highway construction process, together with labour and materials. In most cases, data were collected using a questionnaire prepared, personal interviews and case studies. Construction is a professional region that trusts primarily on high utilization of construction equipment. Equipment is thus one of the key factors for improving experiences in performing work more effectively and efficiently.

After the above study of more than 31 papers from various countries, conclude that more focus on identifying $\&$ evaluating major problems in construction equipment planning, selection, management \& its performance and there effect on construction equipment productivity on highway projects, also studied parameters of respondents classification. Literature has been investigated in order to identify the factors that mostly influencing the productivity of construction equipments in highway projects. Some Key factors which govern Construction of highway project are;
a. Equipment management
b. Selection of equipment
c. Acquisition of Equipment
d. Operation
e. Productivity
f. Maintenance
g. Disposal

Finally, the review of 25 papers, the performance of equipment productivity for highway projects which mainly effect on percentage of involvement of following experts of different position given in below fig. 1 .

Fig. 1 Respondent's classification which are work on various position

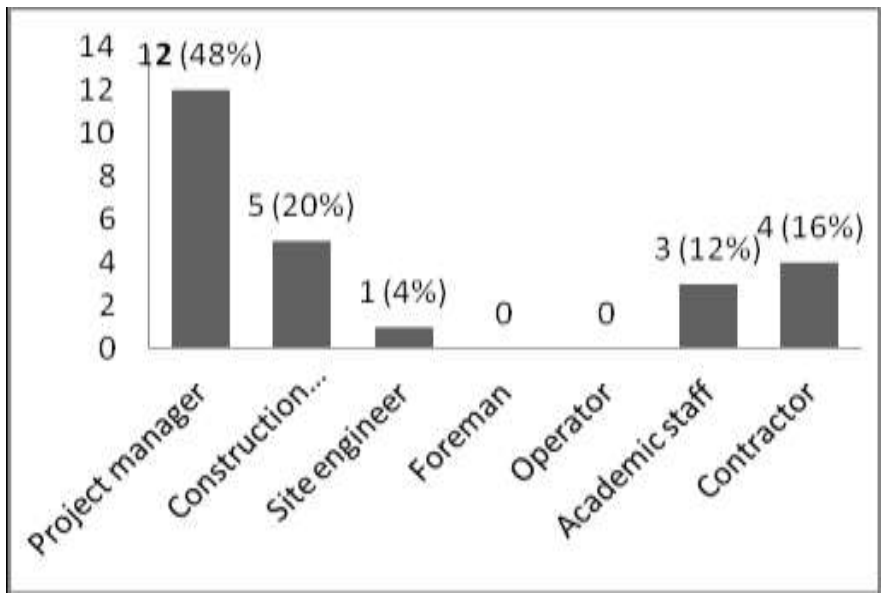

IV. CONCLUSION

1. Equipment plays an important role in today's infrastructure projects as they are more demanding and highway projects are need to be completed in stipulated time with best quality.

2. In most of the research paper, planning, selection, procurement, installation, operation, maintenance and equipment management policy plays an important role in equipment management for successful completion of project.

3. Incorrect equipment selection may directly affect to its productivity for that particular work.

4. Regular repairs and maintenance of equipment may increase its life providing better performance.

5. This study concluded that the proper planning, selection \& management of equipment is the most important thing and it is mostly depend upon the site condition and type of project. Thus, it is important role of construction manager to understand and properly utilize such factors for better performance of equipments.

\section{A. A. Future Scope of the study:}

This research will be concentrated on improving performance of equipment productivity \& studied various parameters which effect on construction equipment planning, selection and management practices for construction of highway projects. Also analyze the equipment planning policies and its management procedures and their impact on the success of highway projects in allpurpose.

\section{ACKNOWLEDGMENT}

I would like to express my gratitude to Dr. P.P. Bhangale who guide me throughout this research work with their support and technical expertise. 
I would like to express special thanks to a person who has been my friend, who had always support me in all things who had helped me in getting my job done, who had encouraged me to go on when things have gone wrong.

I am thankful to my whole family who gives me emotional support throughout my study.

The usefulness of this dissertation is dedicated to my father, mother, wife and all the teachers who have taught me since my childhood.

\section{REFERENCES}

[1] Aakash P. Mohane, Harshita P. Ambre "Equipment planning and management in road construction project", International Research Journal of Engineering and Technology (IRJET), Volume: 06 Issue: 05 May 2019, pp.7561-7567.

[2] Y.R.Anbhule and Prof. M.B.Kumthekar, "3D Equipment Management System for Highway Construction Projects: Conceptual Design", IOSR Journal of Mechanical and Civil Engineering (IOSRJMCE), 2019, ISSN: 2278-1684, PP: 01-03.

[3] M. Manikandan, Prof. M. Adhiyaman, Dr. K.C.PazhaniA , "Study and Analysis of construction equipment management used in construction projects for improving productivity", International Research Journal of Engineering and Technology (IRJET), Volume: 05 Issue: 03, Mar-2018, pp. 1297-1303.

[4] N. Shyamananda Singh, "Construction Equipment Productivity and Cost Economics In Highway Projects: Case Study Part I (Site Specific Study)", International Journal of Advanced Research in Engineering and Technology (IJARET) Volume 9, Issue 3, May June 2018, pp. 154-162.

[5] Mekdim Mathewos, "A Study on Construction Equipment Planning and management problems in Road Construction Project (A case study: The Addis Ababa City Roads Authority)", The School of Civil and Environmental Engineering, Addis Ababa University, Ethiopia, 2017.

[6] Shinde V. J., Hedaoo M. N. "A Review on Productivity Improvement In Construction Industry", International Research Journal of Engineering and Technology (IRJET), Volume: 04 Issue: 11 | Nov -2017, pp. 210215.

[7] Shinde V. J., Hedaoo M. N. "A Review on Productivity Improvement In Construction Industry", International Research Journal of Engineering and Technology (IRJET), Volume: 04 Issue: 11 | Nov -2017, pp. 210215.

[8] Sachin Pindoria, Dr. Jayeshkumar Pitroda, Dr. H.V. Patel,“A Critical Review of Identification of Critical Factors Affecting the Productivity of Construction Equipment", International Journal of Engineering
Research \& Technology (IJERT), Vol. 6 Issue 02, February-2017, pp. 297-301.

[9] Samson Mekbib Atnaw, Lakhveer Singh, Fatwi Yohaness Hagos, Abu Yousuf "Road construction equipment management: a case study on selected industry”, IJETS, Malaysia, 2016.

[10] Atfal Murodif, Erizal " Measurement of Productivity Using Work Sampling Method at Menara Sentraya building Project Jakarta Indonesia" Scholars Journal of Engineering and Technology (SJET), ISSN 2321-435X (Online) Sch. J. Eng. Tech, 2016, pp-244-248.

[11] Kartik Shard Thete, Dhiraj Rajendra Baviskar "Construction Equipment management," International Journal of Science, Engineering and Technology Research (IJSETR), Volume 5, Issue 11, November 2016, pp. 3262-3264.

[12] Prajeesh. V. P. , Mr. N. Sakthivel "Management of Equipment \& Machinery in Construction”, IJISET International Journal of Innovative Science, Engineering \& Technology, Vol. 3 Issue 5, May 2016, pp.113-118.

[13] David Ngwoke Mbazor Sunday Okuoma Okoh,', "Productivity Improvement in Construction Project Delivery", Civil and Environmental Research, Vol.7, No.10, pp. 31-34, 2015.

[14] Prasannasangeetha.A, Alan.S, "Equipment Management In Construction Sector", International Journal of Science and Engineering Research (IJOSER), Vol 3 Issue 6 June -2015.

[15] Saurabh Rajendra Kadam, Prof. Dhananjay S Patil, "Construction Equipment Fleet Management: Case Study of Highway Construction Project", International Journal of Science and Research (IJSR), Volume 4 Issue 6, June 2015, pp. 2558-2564.

[16] K. Shashank, Sutapa Hazra " Analysis of Key Factors Affecting the Variation of Labour Productivity in Construction Projects " , International Journal of Emerging Technology and Advanced Engineering (IJETAE), ISSN 2250-2459, Volume 4, Issue 5, May 2014 pp-152-160.

[17] Abebaw Worku Dagne, "Loss Assessment Of Construction Equipment Productivity And Its Impact On Equipment Financial Performance In Federal Road Projects: A Case Study On Three Federal Asphalt Road Projects In Snnpr", The School of Civil and Environmental Engineering, Addis Ababa University, Ethiopia, 2014

[18]A. R. Dolage, and P. Chan. "Productivity in Construction-A Critical Review of Research" ENGINEER - Vol. XXXXVI, No. 04, 2013,PP. 31-42.

[19] Sri. Nuwan Randunupura, Chandanie Hadiwattege "Plant and Equipment Management to Minimize 
Delays in Road Construction Projections”, Department of Building Economics, University of Moratuwa, Sri Lanka., 2013.

[20] Mohammed Faiz, "Comparative Study of Productivity and Cycle Times of Different Excavators With Respect To Bucket Size," Visvesvaraya National Institute of Technology, Nagpur, 2013.

[21] Parviz Ghoddousi and Mohammad Reza Hosseini, 'a survey of the factors affecting the productivity of construction projects in Iran', Journal of Technological and economic development of economy', 2012, Volume 18(1), pp. 99-116.

[22] Kyong Ju Kim K. and Kyoungmin Kim, 'Case Study on the Evaluation of Equipment Flow at a Construction Site', American Society of Civil Engineers-Journals of Construction Engineering and Management, November 2010, Vol. 24, No. 6, PP. 570-574.

[23] Osama Moselhi, F.ASCE; and Adel Alshibani, Ph.D, "Optimization of Earthmoving Operations in Heavy Civil Engineering Projects", Journal of Construction Engineering and Management (C) ASCE / OCTOBER 2009, pp. 948-954.

[24] Seung C. ok \& Sunil K.Sinha, "Construction equipment productivity estimation using artificial neural network model", 2006 Construction Management and Economics, Vol. 24, pp45.

[25] Aviad Shapira and Marat Goldenberg, "AHP-Based Equipment Selection Models for Construction Projects', American Society of Civil EngineersJournals of Construction Engineering and Management, 2005, Vol. 131, No. 12, PP. 1263-1273

[26] Chiara F. Ferraris, "Concrete Mixing Methods and Concrete Mixers: State of the Art”, National Institute of Standards and Technology, March-April 2001, Vol. 106, pp. 02.

[27] Mitchell W. Zane, “A Statistical Analysis of Construction Equipment Repair Costs Using Field Data \& the Cumulative Cost Model", April 28, 1998, Virginia Polytechnic Institute and State University in partial fulfillment of the requirements for the degree of Doctor of Philosophy in Civil Engineering, pp.20.

[28]Jones, R. P, (2002)“Monitoring Construction Equipment for Automated Project Performance Control", pp.01-05.

[29] Remon F. Aziz, Yasser R. Aboel, "Suitably selection for earthwork equipment In Egyptian sites", International Journal of Education and Research, Vol. 3 No. 1 January 2015,pp.539-550.

[30] S.V.S. Raja Prasada,"Modelling the factors influencing the selection of the construction equipment for India construction organizations", Growing Science Management Science Letters, 2016, pp. 575-584.
[31] A. Jrade, N. Markiz, and N. Albelwi, “An Economical Operation Analysis Optimization Model for Heavy Equipment Selection", International Journal of Economics and Management Engineering, Vol: 6, No:1, 2012, pp. 146-151. 